\title{
SISTEM INFORMASI PENJUALAN SEPEDA MOTOR DEALER SYSTEM PADA PT TUNAS DWIPA MATRA
}

\author{
Kristiantiningsih $^{1}$, Nico Bustanul Anshary ${ }^{2}$, Sri Melati Sagita ${ }^{3}$ \\ ${ }^{1,2,3}$ Universitas Indraprasta PGRI \\ Jl. Raya Tengah No. 80, Kel. Gedong, Kec Pasar Rebo, Jakarta Timur13760, Jakarta

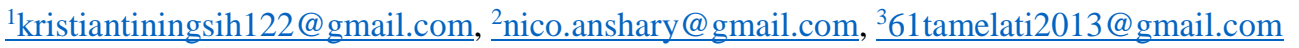

\begin{abstract}
ABSTRAK
Tujuan dari penelitian ini adalah untuk merancang dan menerapkan suatu sistem informasi penjualan sepeda motor berupa aplikasi sistem informasi pengolahan data unit perusahaan yang menunjang semua kebutuhan aspek perusahaan agar terdata semua dan tidak ada kekeliruan data transaksi penjualan dan pembuatan laporannya. Metode penelitian yang digunakan dalam perancangan sistem informasi penjualan sepeda motor dealer system pada PT tunas dwipa matra ini adalah waterfall dengan Metode ini melakukan pendekatan secara sistematis dan urut mulai dari level kebutuhan sistem lalu menuju ke tahap analisis, desain, coding, testing/verification, dan maintenance. Selain itu, peneliti juga melakukan pengambilan data dengan metode kepustakaan berdasarkan referensi dari berbagai media yang memuat infomasi yang dibutuhkan, menganalisis kebutuhan, perancangan, implementasi dan pengujian. Dalam membangun sistem ini, digunakan alat bantu perancangan sistem yaitu Diagram Aliran Data (DAD), Konteks, Nol, Rinci. Sistem informasi yang dirancang ini dapat mempermudah pekerjaan admin pada PT Tunas Dwipa Matra.
\end{abstract}

Kata Kunci: Sistem Informasi, Penjualan, Pengolahan Data

\section{ABSTRACT}

The purpose of this research is to design and implement a motorcycle sales information system in the form of a company unit data processing information system application that supports all aspects of the company's needs so that all data is recorded and there are no errors in sales transaction data and report generation. The research method used in designing a motorcycle dealer system sales information system at PT Tunas Dwipa Matra is the waterfall method. maintenance. In addition, the researcher also collected data using the library method based on references from various media containing the required information, analyzing needs, designing, implementing and testing. In building this system, used system design tools, namely Data Flow Diagrams (DAD), Context, Zero, Detail. This information system designed can facilitate the work of the admin at PT Tunas Dwipa Matra.

Key Word: Information Systems, Sales, Data Processing

\section{PENDAHULUAN}

Perkembangan ilmu pengetahuan dan teknologi saat ini mengubah perusahaan dalam proses penyelesaian masalah operasional. Salah satunya adalah pemanfaatan teknologi sebagai peningkatan produktivitas perusahaan dengan membangun perancangan sistem informasi dan salah satu syarat untuk membangun sistem yang baik yaitu kecepatan, akurasi dan efisiensi dalam pengelolaan informasi atau data perusahaan. Oleh karena itu pemanfaatan teknologi komputer sebagai media dalam membantu perusahaan untuk penyelesaian masalah sangatlah tepat. Perancangan sistem informasi penjualan pada dealer (HONDA) PT Tunas Dwipa Matra dibuat untuk membantu karyawan PT Tunas Dwipa Matra (HONDA) Depok untuk mempermudah transaksi penjualan, mencari informasi data customer, unit yang masuk, keluar dan yang akan dikirim atau dijual. Perancangan dapat diartikan perencanaan dari pembuatan suatu sistem yang menyangkut berbagai komponen sehingga akan menghasilkan sistem yang sesuai dengan hasil dari tahap analisa sistem. (Deddy Ackbar Rianto, Setiawan Assegaf, 2015)

Tujuan dari penelitian ini adalah merancang sistem informasi penjualan sepeda motor yang dapat meminimalisir kesalahan admin dalam melakukan teransaksi penjualan dan pendataan stok unit serta mempermudah dalam pembuatan laporan penjulan. Perancangan adalah langkah pertama dalam fase pengembangan rekayasa produk dan sistem. Perancangan itu adalah proses penerapan berbagai teknik dan prinsip yang bertujuan untuk mendefinsikan sebuah 
peralatan, satu proses atau satu sistem secara detail yang membolehkan dilakukan realisasi fisik(Nadeak et al., 2016)

"Sistem merupakan suatu kumpulan atau kesatuan dari jaringan kerja dari prosedurprosedur yang saling berhubungan, elemenelemen yang saling berkaitan untuk mencapai suatu tujuan tertentu".(Alief maulana, Muhammad sadikin, 2018)

Sistem Informasi adalah kumpulan atau grup dari sub sistem/bagian/komponen atau apapun baik fisik ataupun non fisik yang saling berhubungan satu sama lain dan dapat bekerja sama untuk mencapai satu tujuan tertentu.(Susanto, 2013)

Informasi adalah data yang diolah lebih berguna dan lebih berarti bagi penerimanya. Sumber informasi adalah data kenyataan yang menggambarkan suatu kejadiankejadian dan kesatuan nyata. Kejadiankejadian adalah kejadian yang terjadi pada saat tertentu. (Hutapea, 2015)

Data adalah kenyataan yang menggambarkan suatu kejadian serta merupakan suatu bentuk yang masih mentah yang belum dapat bercerita banyak sehingga perlu diolah lebih lanjut melalui suatu model untuk menghasilkan informasi.(Sutabri, 2012b)

DFD adalah suatu network yang menggambarkan suatu sistem otomatis atau komputerisasi, manualisasi atau gabungan dari keduanya yang penggambarannya disusun didalam bentuk kumpulan komponen sistem yang saling berhubungan sesuai dengan aturan.(Sutabri, 2012c)

Konteks Diagram adalah sebuah diagram sederhana yang menggambarkan hubungan antara entity luar, masukan, dan keluaran dari system. Diagram konteks direpresentasikan dengan lingkaran tunggal yang mewakili keseluruhan system. (Sutabri, 2012a)

Model berikutnya yang akan dibahas adalah data dictionary/ DD (Kamus Data/KD). KD tidak menggunakan notasi grafis sebagimana halnya DFD, KD juga mempunyai fungsi yang sama dalam pemodelan sistem, yaitu sebagi katalog data dan kebutuhan-kebutuhan informasi dari suatu sistem informasi. (Mainah, 2019)

Berdasarkan penjelasan di atas, dirancanglah sistem informasi penjualan pada PT. Tunas Dwipa Matra. Dengan menggunakan sistem informasi ini, proses pengolahan data dan laporan penjualan akan lebih efesien, serta tingkat kepuasan pelanggan akan meningkat terhadap pelyanan PT. Tunas Dwipa Matra.

\section{METODE PENELITIAN}

Metode penelitan yang digunakan yaitu metode penelitian Waterfall merupakan salah satu metode pengembangan sistem informasi yang bersifat sistematis dan sekuensial, artinya setiap tahapan dalam metode ini dilakukan secara berurutan dan kelanjutan. Waterfall model sebagai salah satu teori dasar dan seakan wajib dipelajari dalam konteks siklus hidup perangkat lunak.

Penelitian ini di PT. Tunas Dwipa Matra yang beralamat di Jalan Raya Tapos Cimpaeun Rt. 005 Rw. 002 Cimpaeun, Tapos, Depok, Jawa Barat 16457 dimulai selama 4 bulan dari mulai April 2021 sampai dengan bulan Juli 2021.

Bahasa pemrograman yang digunakan adalah java. Java merupakan bahasa berorientasi objek untuk pengembangan aplikasi mandiri, aplikasi berbasis internet, aplikasi untuk perangkat cerdas yang dapat berkomunikasi lewat internet/ jaringan komunikasi dan merupakan bahasa pemrograman yang dikembangkan dari bahasa pemrograman $\mathrm{C}++$, sehingga bahasa pemrograman ini seperti bahasa pemrograman $\mathrm{C}++$. (Haryanto, 2011) Netbeans merupakan sebuah aplikasi Intergrated Development Environment (IDE) yang berbasiskan Java dari Sun Microsystems yang berjalan diatas swing.

MySQL adalah sebuah perangkat lunak system manajemen basis data SQL (Database Management System) atau DBMS yang multithread, multi-user. 
Aplikasi pengembang yang digunakan adalah XAMPP. XAMPP merupakan suatu software yang bersifat open source yang merupakan pengembangan dari LAMP (Linux, Apache, MySQL, PHP dan Perl).

\section{HASIL DAN PEMBAHASAN}

Berdasarkan hasil penelitian, peneliti memberikan permasalahan dari sistem penjualan di anataranya:

1. Lambatnya pelaksanaan oprasional proses transaksi penjualan dikarenakan masih manual. Dalam proses perhitungan transaksi diskon dibutuhkan sistem baru lebih efisien.

2. Sering terjadi kekeliruan dan kesalahan pada saat mengolah data unit dikarenakan masih menggunakan penghitungan manual belum terintegrasi database.

3. Sering terjadi keterlambatan dalam pembuatan laporan dikarenakan hanya tersedia untuk unit yang terjual sehingga untuk membuat laporan secara keseluruhan harus secara manual.

Berdasarkan masalah yang terdapat pada PT. Tunas Dwipa Matra, penulis memberikan beberapa alternatif penyelesaian masalah sebagai berikut.

1. Merancang sistem informasi yang mudah dipahami sehingga dapat menampilkan informasi data penjualan secara cepat dan tepat.

2. Merancang sistem informasi penjualan dan stok barang dengan sistem basis data secara relasional yang dapat di atur hak aksesnya.

3. Merancang database untuk data penjualan dan data pelanggan sehingga penyimpanan data tidak menggunakan media kertas atau sistem yang lama.

\section{Diagram Konteks Sistem yang Diusulkan \\ Berikut adalah gambaran sistem yang diusulkan untuk PT. Tunas Dwipa Matra :}

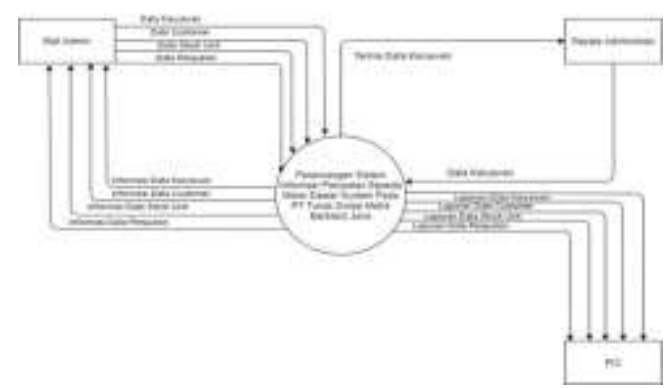

Gambar 1. Diagram Konteks Sistem yang Diusulkan

\section{Diagram Nol Sistem}

Diagram nol merupakan gambaran proses sistem berjalan pada setiap penjualan yang mengambarkan tehap-tahap proses dari diagram konteks, yaitu :

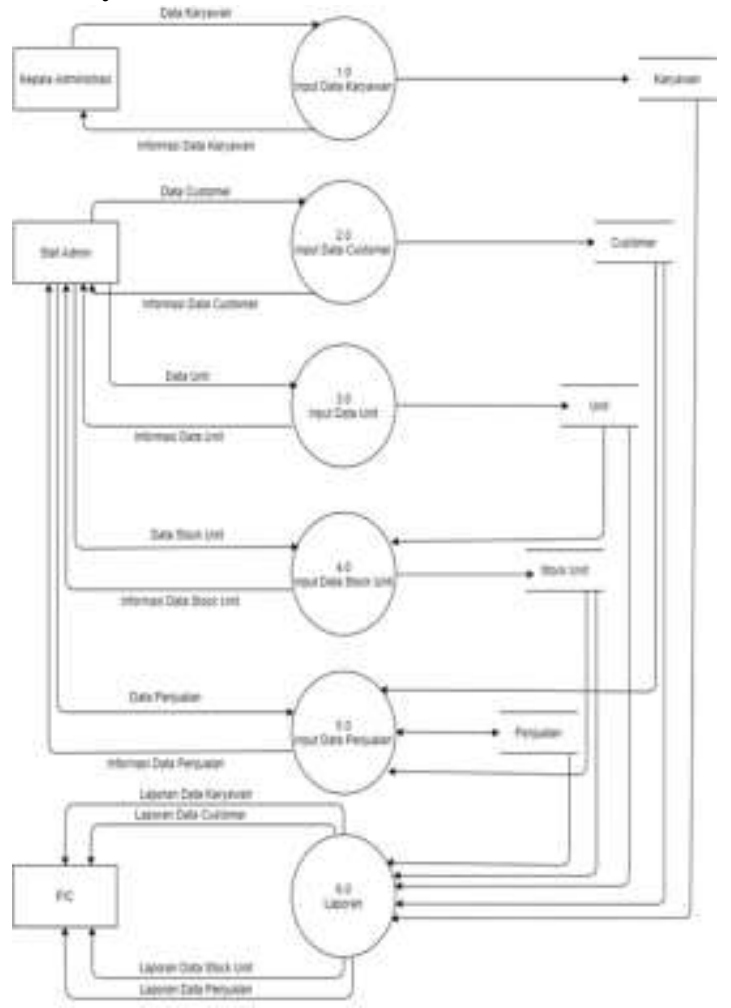

Gambar 2. Diagram Nol Sistem

\section{Entity Relationship Diagram (ERD)}

Berikut adalah ERD hubungan antar data dalam basis data berdasarkan objek-objek dasar data yang mempunyai hubungan antar relasi. 


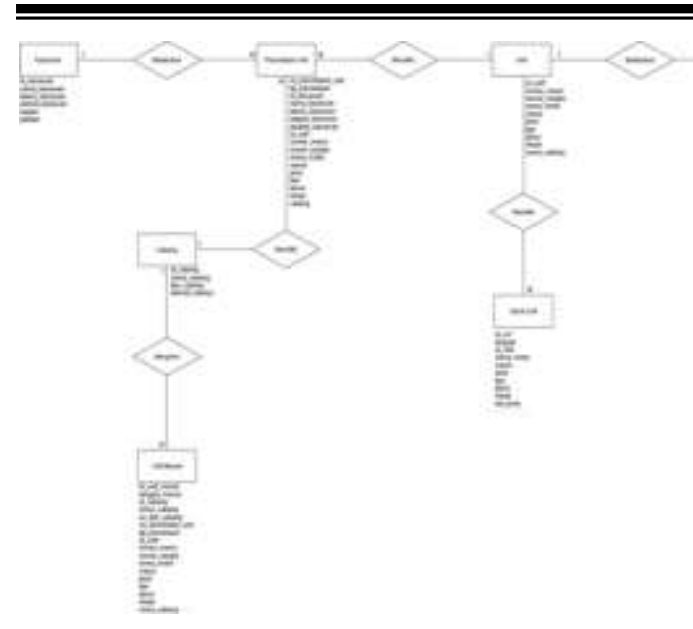

Gambar 3. ERD

\section{Normalisasi Tahap Pertama}

Normalisasi tahap pertama, suatu relasi atau tabel memenuhi normal pertama jika dan hanya jika setiap setiap atribut dari relasi tersebut hanya memiliki nilai tunggal dalam satu baris (record).

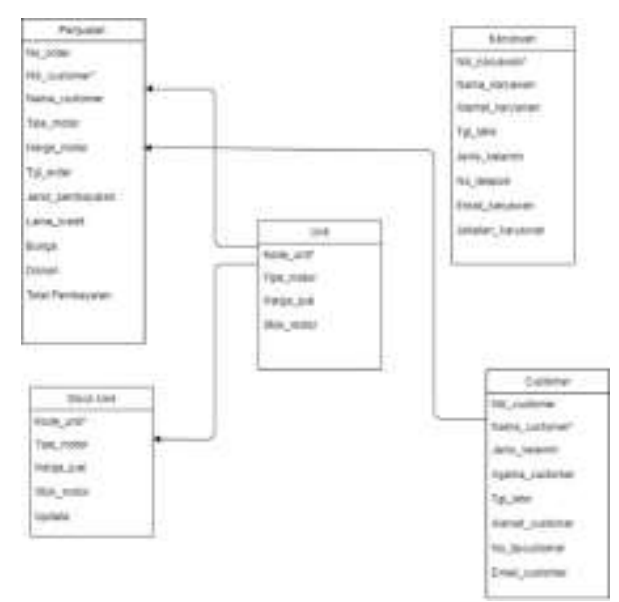

Gambar 4. Normalisasi Tahap Pertama (1NF)

\section{Normalisasi Tahap Kedua (2NF)}

suatu relasi memenuhi relasi kedua jika dan hanya jika relasi tersebut memenuhi normal pertama dan setiap atribut yang bukan kunci (non key) bergantung secara fungsional terhadap kunci utama (Primary key).

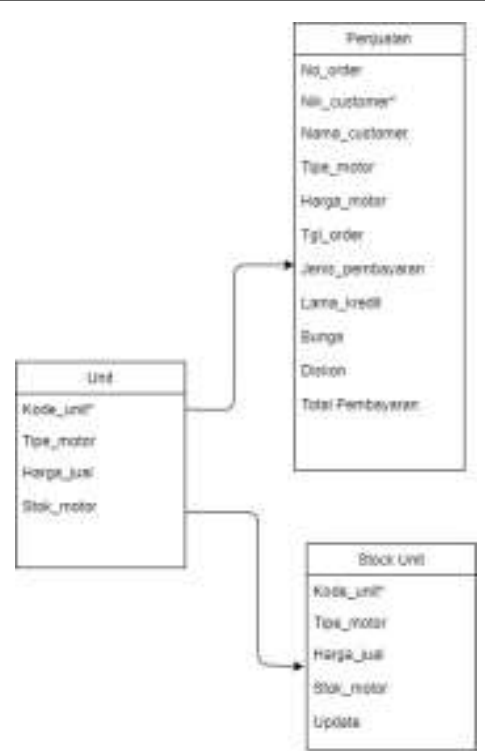

Gambar 5. Normalisasi Tahap Kedua (2NF)

Tampilan Menu Login

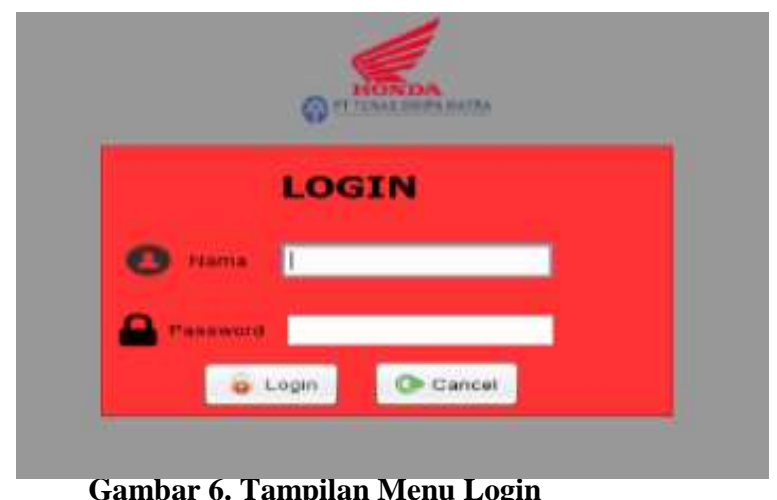

Pada tampilan awal menjalankan aplikasi ini menampilkan form login. Pengguna diharuskan memasukkan username dan password agar dapat masuk ke halaman menu utama.

\section{Tampilan Menu Utama}

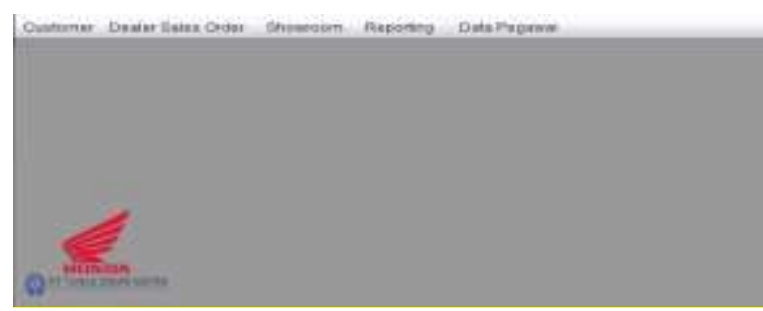

Gambar 7. Tampilan Menu Utama

Pada tampilan ini menampilkan menu utama dan terdapat pilihan menu yaitu customer, data unit, data pengguna, stok unit dan laporan. 


\section{Tampilan Form Customer}

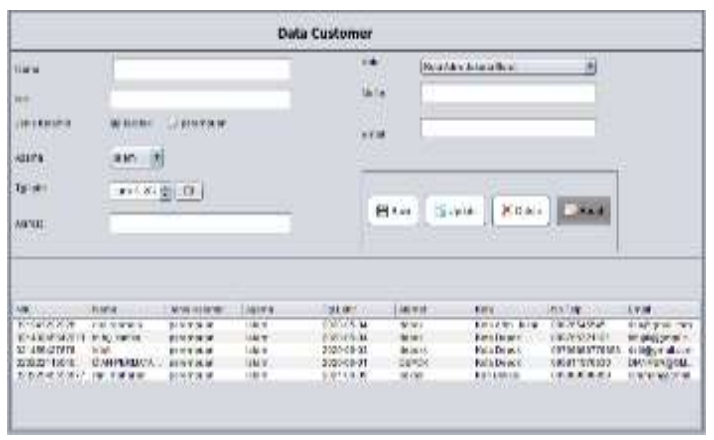

Gambar 8. Tampilan Form Customer

Pada tampilan ini menampilkan data customer yang dapat ditambahkan dan diubah.

\section{Tampilan Form Penjualan}

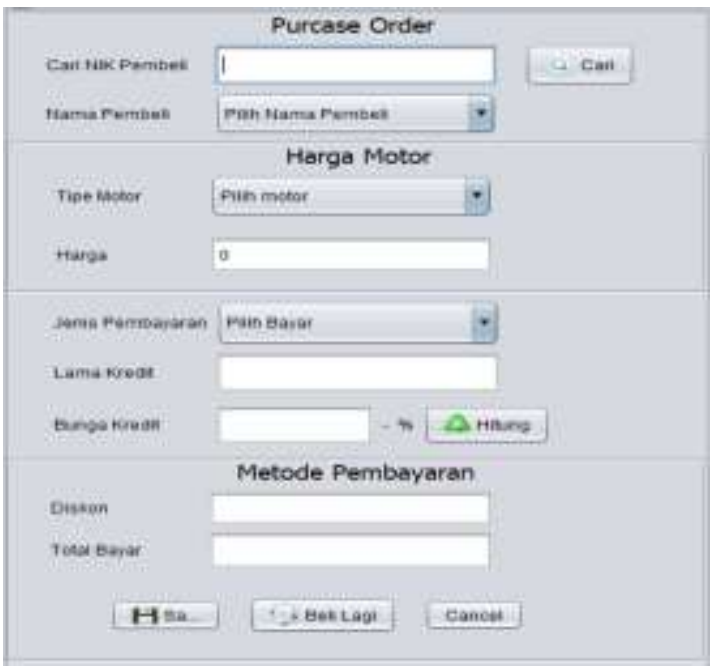

Gambar 9. Tampillan Form Penjualan

Pada tampilan ini menampilkan data penjualan yang dapat melihat data penjualan ke customer.

\section{Tampilan Form Data Penjualan}

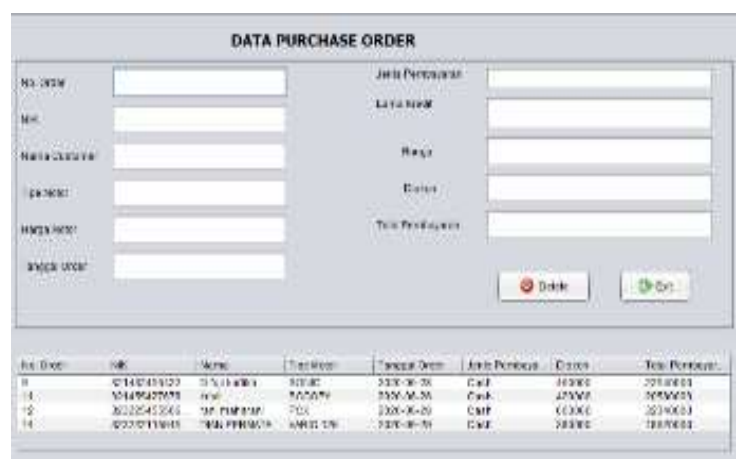

Gambar 10. Tampilan Data Penjualan
Pada tampilan ini menampilkan input data penjualan yang dapat menambahkan data penjualan ke customer

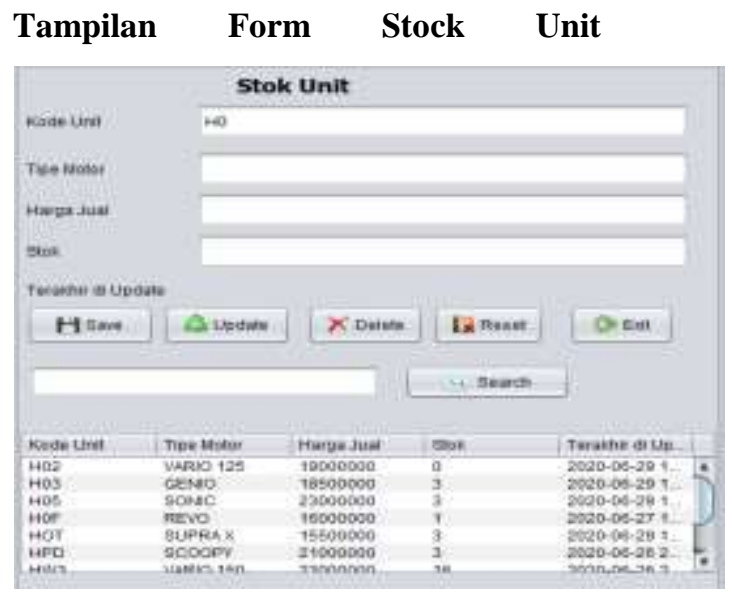

\section{Gambar 11. Tampilan Form Stock Unit}

Pada tampilan ini menampilkan form stok unit yang bisa menambahkan data stok unit barang.

\section{Tampilan Form Data Karyawan}

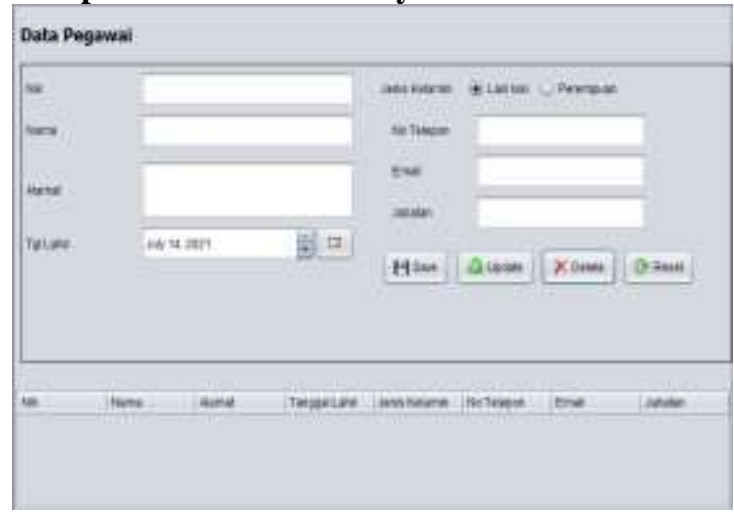

Gambar 12. Tampilan Form Karyawan

Pada tampilan ini menampilkan form data karyawan yaitu untuk menambahkan data karyawan.

\section{Tampilan Form Laporan Karyawan}

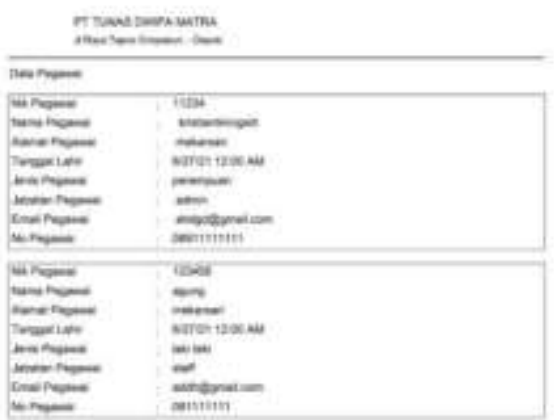

Gambar 13. Tampilan Laporan Karyawan 
Pada tampilan ini menampilkan Laporan data karyawan PT Tunas Dwipa Matra.

\section{Tampilan Laporan Customer}

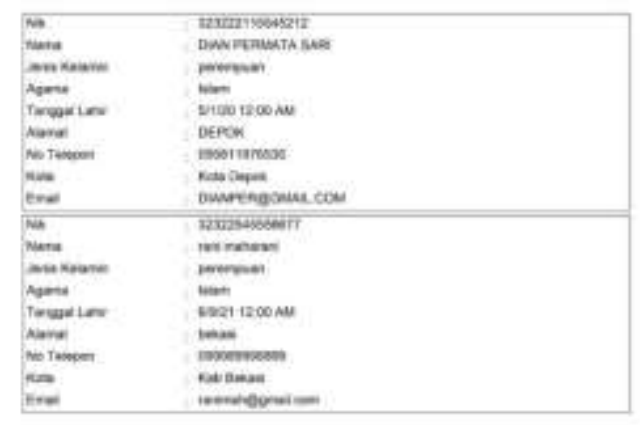

\section{Gambar 14. Tampilan Laporan Customer}

Pada tampilan ini menampilkan Laporan dari data customer.

\section{Tampilan Laporan Stock Unit}

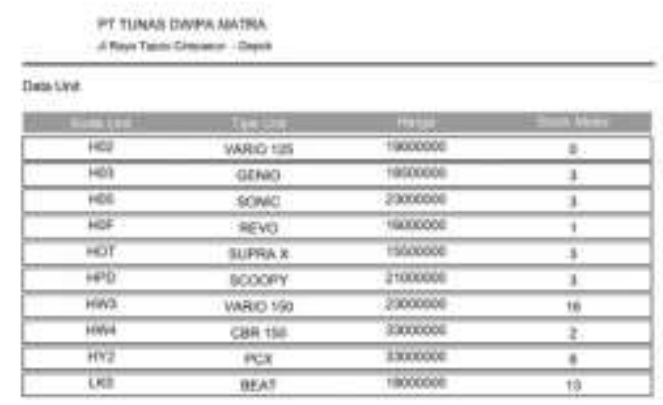

Gambar 15. Tampilan Laporan Stock Unit

Pada tampilan ini menampilkan hasil Laporan stok unit barang yang tersedia.
Tampilan Laporan Penjualan

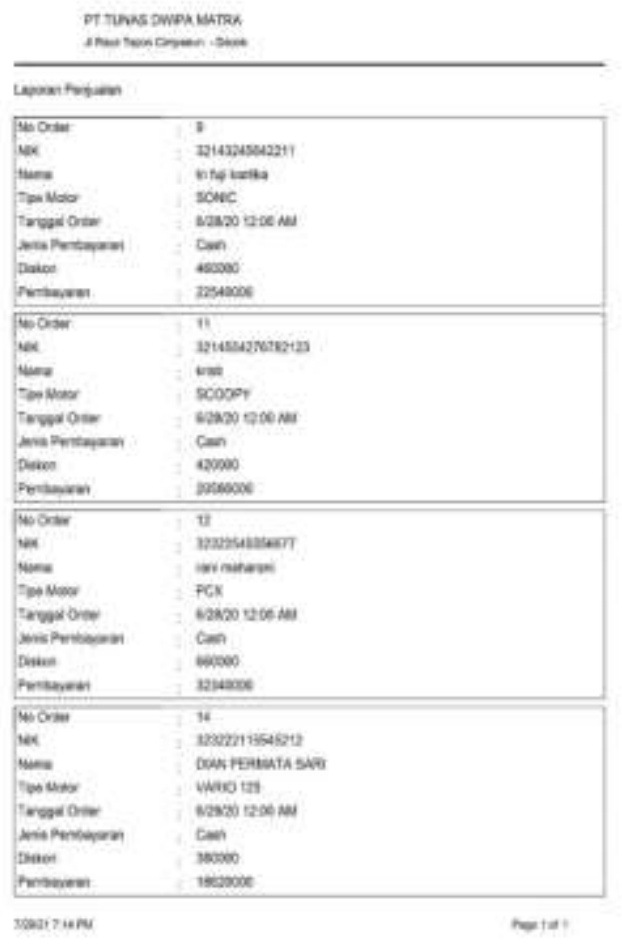

Gambar 16. Tampilan Laporan Penjualan

Pada tampilan ini menampilkan hasil Laporan dari penjualan PT. Tunas Dwipa Matra.

\section{SIMPULAN DAN SARAN}

Berdasarkan penelitian yang telah dilakukan penulis mengenai perancangan sistem informasi penjualan penjualan sepeda motor dealer system pada PT Tunas Dwipa Matra, dapat diambil simpulan sebagai berikut :Sistem informasi penjualan sepeda motor dealer system pada PT Tunas Dwipa Matra ini dapat memberikan kemudahan dalam proses transaksi penjualan pada PT Tunas Dwipa Matra.

Pelayanan admin memberikan kemudahan dalam melakukan pengolahan data stock unit karena proses pendataan stock unit dilakukan secara real time yang lebih efesien dan akurat. Dengan adanya sistem informasi penjualan sepeda motor dealer system pada PT Tunas Dwipa Matra ini mempermudah proses laporan akan semakin cepat dan akurat. 
Sejalan dengan sistem yang penulis buat, agar tujuan dan sasaran yang diharapkan bisa tercapai, penulis dapat memberikan saran saran sebagai berikut: Fitur yang ada telah dapat mengatasi permasalahan yang ada pada sistem terdahulunya. Namun, seiring berjalannya waktu, perkembangan bisnis pada perusahaan juga akan semakin meningkat. Oleh karena itu, diperlukan pengembangan yang lebih lanjut terhadap fitur-fitur yang telah ada.

Perawatan juga perlu dilakukan agar program ini dapat digunakan semaksimal mungkin serta perlu dilakukan penyesuaian terhadap sistem.

Hasil penelitian ini selaras dengan hasil penelitian yang menyimpulkan bahwa dengan tidak adanya sistem informasi yang secara terpadu membuat kegiatan oprasional kantor kurang efesien. Hal tersebut disebabkan karena belum adanya sistem informasi secara terpadu serta database penyimpanan peralatan yang kemudian menampilkan laporan.

\section{DAFTAR PUSTAKA}

alief Maulana, Muhammad Sadikin, A. Izzuddin. (2018). Implementasi Sistem Informasi Manajemen Inventaris Berbasis Web Di Pusat Teknologi Informasi Dan Komunikasi-Bppt. Sistem Kendali-Tenaga-ElektronikaTelekomunikasi-Komputer, Vol 07 No.

Deddy Ackbar Rianto, Setiawan Assegaf, E. F. (2015). Perancangan Aplikasi Sistem Informasi Goeografis (Sig) Lokasi Minimarket Di Kota Jambi Berbasis Android. Jurnal Ilmiah Media Sisfo, Vol 09 No.

Haryanto, B. (2011). Esensi-Esensi Bahasa Pemrograman Java. Andi.

Hutapea, J. (2015). Konsep Sistem Informasi. Deepublish.

Mainah, H. (2019). Analisis Dan Perancangan Sistem Informasi Pembahasan Secara Praktis Dengan Contoh Kasus. Deepublish.

Nadeak, B., Parulian, A., Pristiwanto, \& Siregar, S. R. (2016). Perancangan Aplikasi Pembelajaran Internet Dengan Menggunakan Metode Computer Based Instruction. Jurnal Ilmiah Media SISFOurnal Riset Komputer (JURIKOM), Vol 03 No.

Susanto, A. (2013). Sistem Informasi Akuntansi. Lingga Jaya.

Sutabri, T. (2012a). Analisis Sistem Informasi. Andi Offset.

Sutabri, T. (2012b). Konsep Dasar Sistem. Andi Offset.

Sutabri, T. (2012c). Konsep Dasar Sistem. Andi Offset. 